\title{
Fishbone perforation of the gastrointestinal tract in patients with acute abdominal pain: diagnosis using plain film radiography
}

\author{
Fang-Jy Su, ${ }^{1}$ I-Li Lin, ${ }^{2}$ Yuan-Horng Yan, ${ }^{3}$ Chun-Lin Huang ${ }^{2,4}$
}

1 Department of Internal Medicine, Ditmanson Medical Foundation Chiayi Christian Hospital, Chiayi, Taiwan 'Department of Radiology, Ditmanson Medical Foundation Chiayi Christian Hospital Chiayi, Taiwan

${ }^{3}$ Department of Medical Research, Chiayi Christian Hospital, Chiayi, Taiwan ${ }^{4}$ Department of Radiology, China Medical University Hospital, Taichung, Taiwan

\section{Correspondence to}

Dr Yuan-Horng Yan, r92841010@gmail.com

Accepted 12 May 2014

\section{DESCRIPTION}

Most foreign bodies (FBs) in the gastrointestinal (GI) tract pass spontaneously through it. However, $10-20 \%$ of patients require endoscopic removal, and approximately $1 \%$ will develop perforation of the GI tract requiring surgical intervention. CT is the method of choice for identifying ingested FBs. ${ }^{1}$ However, because CT scanning can be time consuming, an abdominal plain radiograph (plain film) may be helpful in first-line screening of FBs with specific shapes, such as fish and chicken bones. ${ }^{2}$ We report 2 cases of GI perforation by a clinically unsuspected fishbone which was detected by conventional plain film. The first case was a 58 -year-old woman with acute diffuse abdominal pain of 1 day's duration. Plain film showed a linear calcified density, compatible with a fishbone, in the right abdomen (figure 1A). CT confirmed that a fishbone had perforated the small bowel on the right side (figure 1B). The second case was a 60 -year-old man with a right lower abdominal pain of 1 day's duration. Plain film showed an FB resembling a fishbone in the right lower quadrant of the abdomen (figure 2A), which was confirmed by abdominal CT (figure 2B). Plain film radiography shows the specific shape of radiopaque objects, which helps clinicians to diagnosis FB induced GI perforation. ${ }^{3}$ Patients with acute abdominal pain often do not remember ingesting a fishbone, which further lowers the index of clinical suspicion. Indeed, neither of our patients remembered ingesting a fishbone. These two cases show that early presentation of bowel perforation due to the presence of a fishbone may be limited to non-specific abdominal pain. The only hint before CT confirmation was a linear, calcified lesion on plain film. Perforated bowel requires immediate surgery. Careful reading of plain films, before CT confirmation, from patients with acute abdominal pain might prevent delayed and missed diagnoses.

\section{Learning points}

- $\mathrm{CT}$ is the method of choice for identifying ingested foreign bodies (FBs).

- Abdominal plain radiographs may be helpful in first-line screening of FBs with specific shapes.

- Patients often do not remember ingesting fishbones, which lowers the index of clinical suspicion. Careful reading of plain films, before CT confirmation, from patients reporting acute abdominal pain could prevent delayed and missed diagnoses.
To cite: Su F-J, Lin I-L, Yan Y-H, et al. BMJ Case Rep Published online: [please include Day Month Year] doi:10.1136/bcr-2014204201
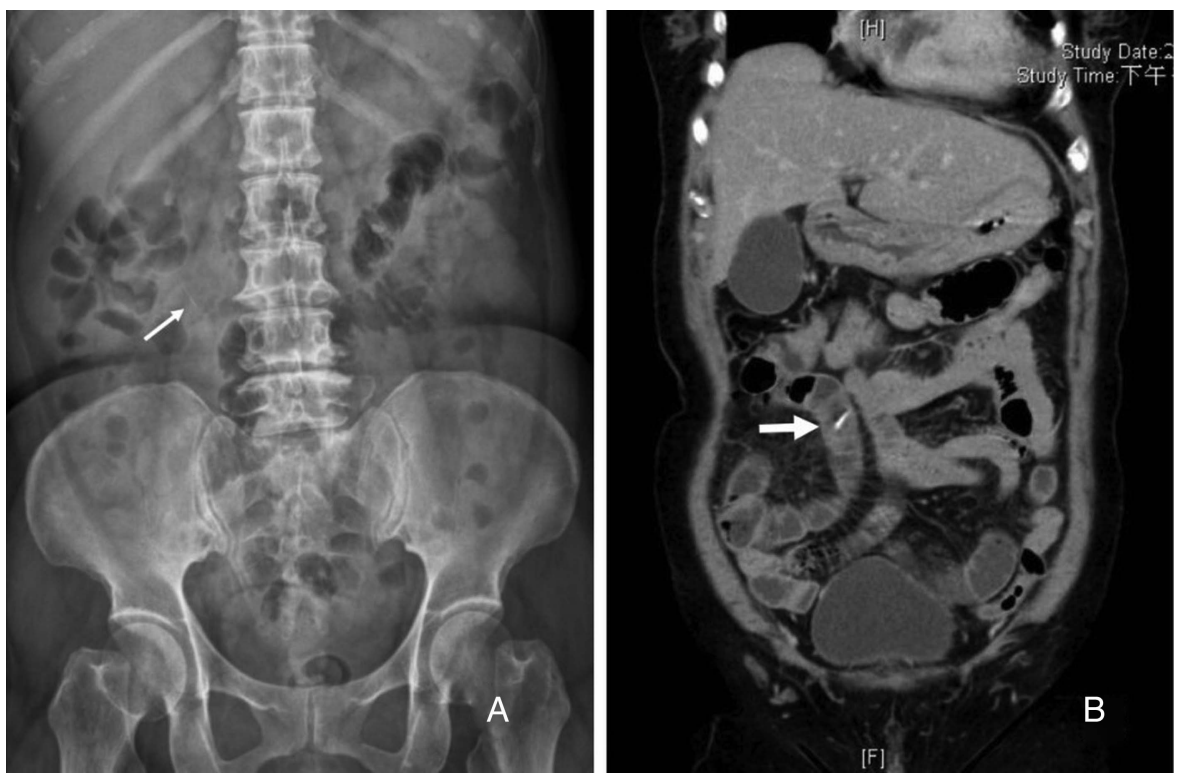

Figure 1 Abdomen plain radiograph showing a fishbone-like foreign body in the right abdomen (thin arrow) (A) and a CT scan showing a foreign body (fishbone) and perforation in the small bowel on the right side (B). 
Figure 2 Abdomen plain film radiograph showing a fishbone-like foreign body (thin arrow) (A) and a CT scan showing a linear, high-density region in the caecum (arrow) and a small abscess (B).
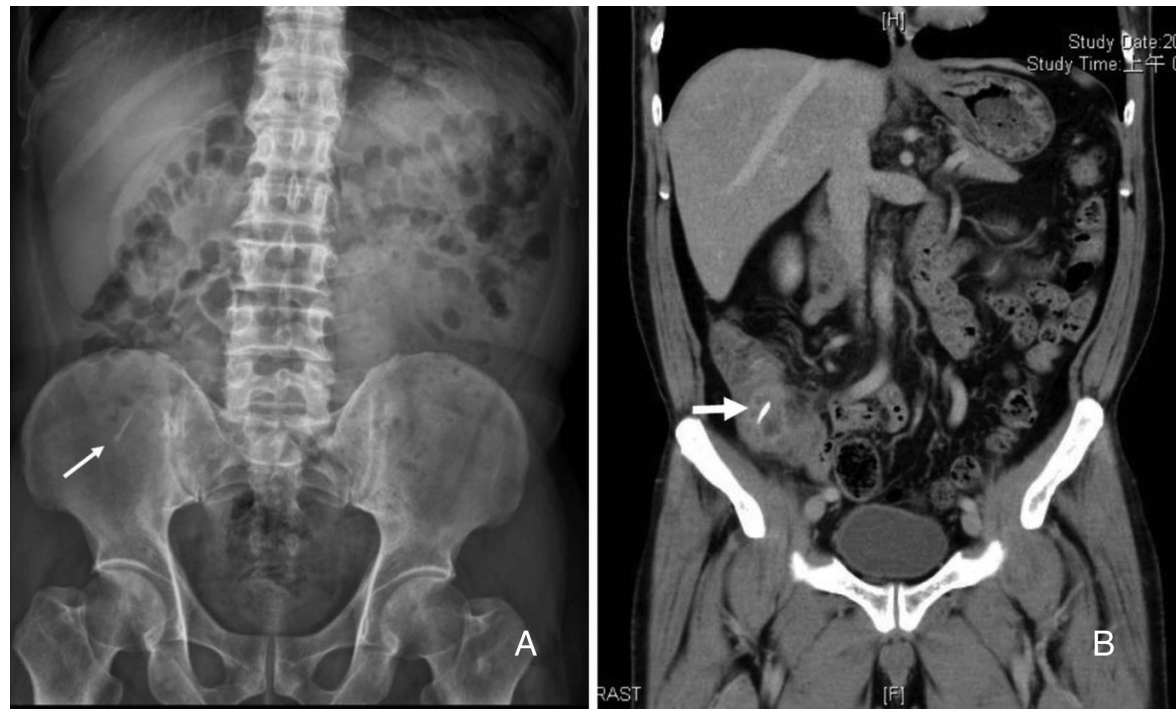

Contributors C-LH and I-LL provided the information and images. F-JS and Y-HY wrote the manuscript.

Competing interests None.

Patient consent Obtained.

Provenance and peer review Not commissioned; externally peer reviewed.

\section{REFERENCES}

1 Coulier B, Tancredi MH, Ramboux A. Spiral CT and multidetector-row CT diagnosis of perforation of the small intestine caused by ingested foreign bodies. Eur Radiol 2004;14:1918-25.

2 Ell SR, Sprigg A, Parker AJ. A multi-observer study examining the radiographic visibility of fishbone foreign bodies. J $R$ Soc Med 1996;89:31-4.

3 Ngan JH, Fok PJ, Lai EC, et al. A prospective study on fish bone ingestion. Experience of 358 patients. Ann Surg 1990;211:459-62.

Copyright 2014 BMJ Publishing Group. All rights reserved. For permission to reuse any of this content visit http://group.bmj.com/group/rights-licensing/permissions.

BMJ Case Report Fellows may re-use this article for personal use and teaching without any further permission.

Become a Fellow of BMJ Case Reports today and you can:

- Submit as many cases as you like

- Enjoy fast sympathetic peer review and rapid publication of accepted articles

- Access all the published articles

- Re-use any of the published material for personal use and teaching without further permission

For information on Institutional Fellowships contact consortiasales@bmjgroup.com

Visit casereports.bmj.com for more articles like this and to become a Fellow 